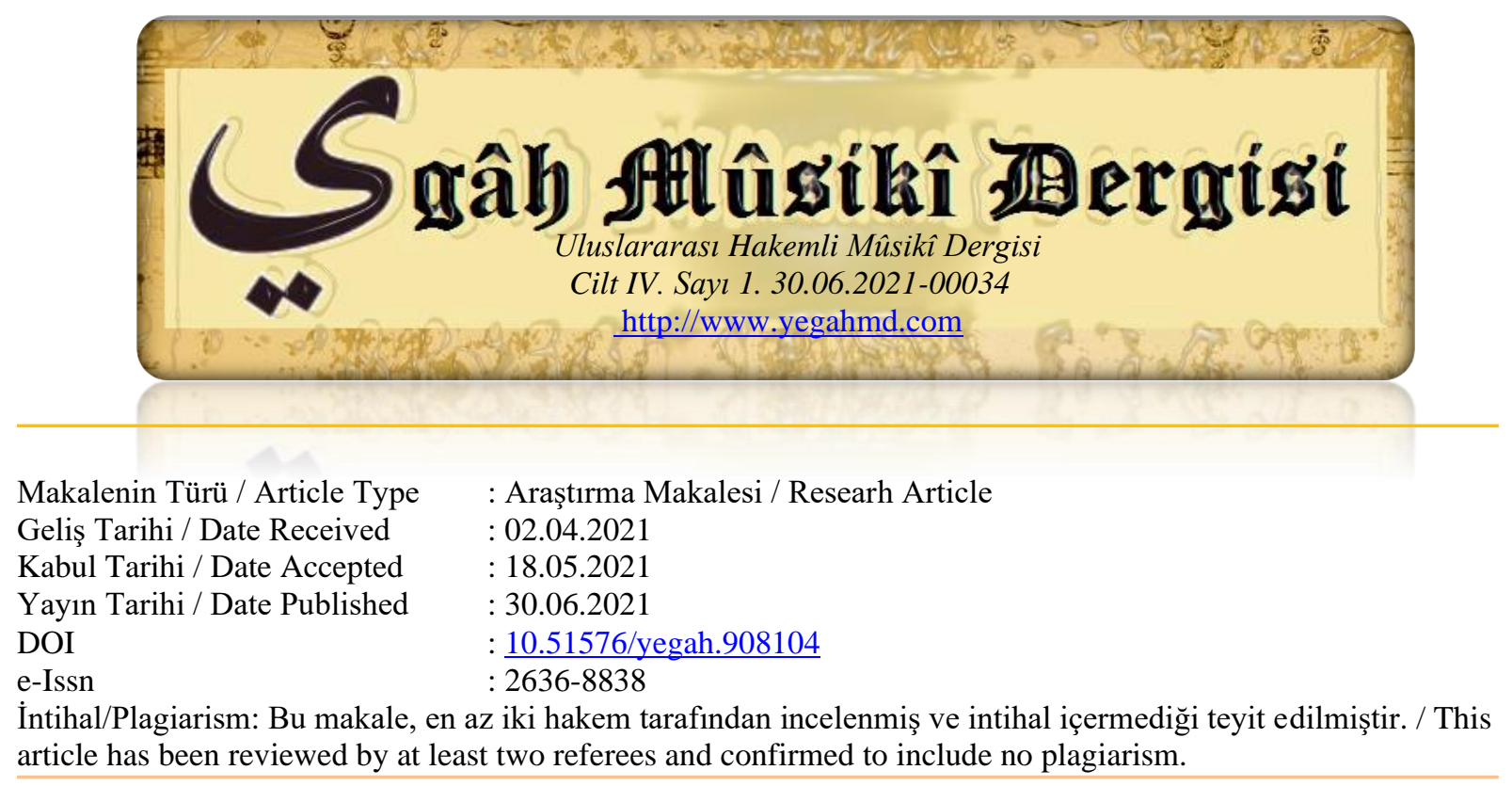

\title{
HÂNENDE VE SÂZENDE NASİB HANIM
}

DEMİRDİ Mahmut ${ }^{1}$

\section{ÖZ}

Bu çalışma, ülkemizde taş plak kaydında öncü kadınlardan olan ilk hânende Nasib Hanım hakkında bir incelemedir. Nasib Hanım, müzisyenlerimiz arasında Türkiye'de taş plağa kaydı alınan ilk kadın hânende olarak bilinmektedir. Kendisi, dönemin piyasa müziğinde adından sıkça bahsettirmiş, hemen hemen her gece bir başka konakta tok sesiyle hânendelik ve sâzendelik icra etmiştir. Piyasada ismini duyursa da emsallerine nazaran musiki dünyasındaki ismini ve önemini; kardeşi olan Nasibin Mehmet Bey’in adıyla günümüze kadar taşımıştır. Araştırmalarımız neticesinde hânende ve sâzende Nasib Hanım hakkında ayrıntılı, müstakil bir çalışmanın yapılmadığg görülmüştür. Bu araştırmada, Nasib Hanım hakkında literatür taraması yapılarak onun önemi, musikiye dair katkısı, sesi, enstrümanı gibi hususlar incelenmiştir. Bulguların elde edilmesinde döküman/belgesel tarama tekniğinden yararlanılmıştır. Bu amaç doğrultusunda elde edilen veriler değerlendirilmiş ve ortaya çıkan bulgular incelenerek bir araya getirilmeye çalışılmıştır. Bu çalışmanın; hakkında pek bilgi bulunmayan Nasib Hanım ile ilgili literatüre

\footnotetext{
${ }^{1}$ Mahmut DEMİRDIL, Bartın Üniversitesi, İslami İlimler Fakültesi, 3.Sınıf Lisans Öğrencisi, 17010803019@ogrenci.bartin.edu.tr (1) https://orcid.org/0000-0002-0399-7913.
} 
önemli bir katkı sağlayabileceği gibi, diğer değerli kadın musikişinaslar hususunda da yeni çalışmalara teşvik unsuru olabileceği düşünülmektedir.

Anahtar Kelimeler: Çingene, Plak, Hanende, Sazende, Nasib Hanım.

\title{
SINGER AND INSTRUMENT PLAYER NASIB HANIM
}

\begin{abstract}
This study is an investigative research on Nasib Hanım, the first singer, who is one of the pioneer women in the gramophone record in our country. Nasib Hanım is known as the first female singer who performed a recording on a gramophone record in Turkey among our musicians. She made a distinguished name for herself in the music industry of the period and appeared as an instrument player and singer with her rich voice in another mansion almost every night. Although she got famous in the industry by herself, her name and importance in the world of music have survived until today thanks to the name of his brother Nasibin Mehmet Bey, compared to her counterparts. As a result of our research, it was observed that a detailed and independent study has not been performed on the singer (hanende) and instrument player (sazende) Nasib Hanım. In this study, a literature review was performed on Nasib Hanım and points such as her importance, her contribution to music, her voice, and her instrument were investigated. The documentary research method was used in obtaining the findings. In line with this purpose, the data obtained were evaluated, and the findings were investigated and tried to be gathered. It is believed that this study can make an important contribution to the literature on Nasib Hanım, about whom there is not much information, as well as being an incentive for new studies to be performed on other valuable female musicians.
\end{abstract}

Keywords: Gypsy, Record, Singer, Instrument player, Nasib Hanım. 


\section{GíRiş}

Osmanlı İstanbul'unun en eski tarihine sahip olan Çingene topluluğu şüphesiz en fazla müzik alanında ön plana çıkmıştır. Dönemin sâzende ve hânendeliği daha çok yerleşik olan çingeneler tarafindan icra edilirken, bu topluluktan piyasada meşhur olan önemli musikişinaslar da Lonca, Sulukule ve Selamsız mahallelerinde yetişmiştir. Gerek enstrüman çalmada gerek bestecilikte piyasaya hâkim oldukları görülen Çingene topluluğunda elbette kadın hânende ve sâzendeler de meşhur olmuştur (Yılgür: 2006, 36). Kendisi de Çingene asıllı olan Nasib Hanım, sanat camiasında birçok bestesiyle tanınmış, yer etmiş olan udi bestekar Nasibin Mehmet Yürü'nün ablasıdır. Nasib Hanım, pek tanınmasa da "Yürü" soyadını alan kardeşi Nasibin Mehmet Yürü’nün isminde yaşamıştır. Nasib Hanım ile kardeşi Mehmet Bey'in babası Kanlıcalı Hüseyin'dir (Derviş Hüseyin Efendi), annesi ise Nefise Hanımdır. Soyadı hususunda kaynaklarda "Yürü" ve "Hasyürü" olarak iki şekilde geçtiğini de belirtmek gerekir (Güntekin: 2010, 100). Nasib Hanım'ın doğum tarihi kaynaklarda belirtilmemiş olsa da kardeşi Mehmet Bey'in 1882 y1lında İstanbul'da doğduğu bilinmektedir. Nasib Hanım'ın doğum tarihinde bir tahminde bulunulacak olunursa: 5 Eylül 1934 tarihli bazı gazetelerde verilmiş olan konser ilanında kendisinin 80 yaşında olduğu belirtilmiştir. $\mathrm{Bu}$ gazeteler hakkında aşağıda bilgiler verilecektir. Bu durumda kendisinin 1854 yılında doğduğu anlaşılmaktadır.

Kaynaklarda Nasib Hanım'a ait tek fotoğraf bulunsa da onun fiziksel özelliklerinden şu şekilde bahsedilebilir; Kara kaşlı, kara gözlü, esmer, kısa boylu, hafif kilolu, yürüyüşü düzgün ve sesi kalıncadır (Ünlü: 2016, 142). Mehmet Bey'in müziğe olan merak1 ve sevgisi şüphesiz hânende ve sâzende olan ablası sayesinde olmuştur. Bu gelişimi sadece ablası ile sınırlı kalmayarak dönemin önemli isimleri olan Âmâ Ali Efendi, Arşak Çömlekçiyan, Kemençeci Vasilaki Efendi ve Kemânî Memduh Efendi'den de meşkler etmiştir (Öztuna: 1987, 85-86). Mehmet Bey kendi kendine ud çalmayı öğrenerek kendisini yetiştirmiş, ablasıyla beraber küçük yaşlarda iken düğünlere katılmış ve ilerleyen yaşlarında dönemin tanınmış sâzendeleri olan Udi Arşak, Kemani Tatyos gibi daha birçok usta ile düğünlerde ud icra ederek piyasada ismini duyurmuştur. Mehmet Bey musikimize 500'den fazla eser kazandıran değerli bir musikişinastır (İnal: 1958, 229). Ölüm tarihi hususunda kaynaklarda farklı bilgilerin mevcut olduğu görülmüştür. Bazı kaynaklarda 20 Ocak 1953 tarihi belirtilirken bazı kaynaklarda ise 15 Kasım 1953 tarihi görülmektedir. Nasibin Mehmet Yürü, ablasının desteği ve katkılarıyla musiki alanında adını duyurabilmiştir. Fakat Nasib Hanım'ın 
ülkemizdeki plak kayıtları tarihinde önemli bir yeri olmasına rağmen pek bilinmemesi dikkatimizi çekmiş ve bizi bu araştırmaya sevk etmiştir.

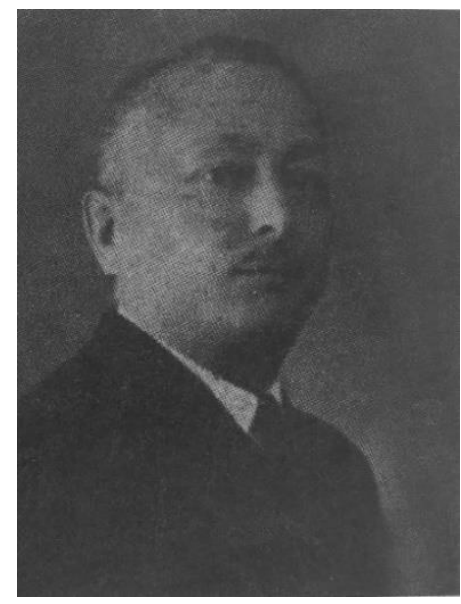

Fotoğraf 1. Nasib Hanım'ın kardeşi Mehmet Bey.

\section{Problem Durumu}

“Ablasının desteği ve katkılarıyla musiki alanında adını duyurabilmiş olan Nasibin Mehmet Yürü’ye rağmen Nasib Hanım'ın pek bilinmemesinin nedeni ve bunun aydınlatılması "cümlesi bu araştırmanın problem cümlesini oluşturmaktadır.

\section{Araştırmanın Amacı}

Çalışmanın amacı, Türkiye'de gramofon plaklarıyla ses kaydının başlangıcında önemli bir yeri olan, hânende ve sâzendeliği ile piyasada adını ve sesini duyurarak beğeniler toplamış, fakat hakkında ayrıntılı, müstakil bir çalışmanın yapılmadığı görülen değerli bir musikişinas Nasib Hanım ile ilgili literatüre katkı sağlamaktır.

\section{Araştırmanın Önemi}

Hânende-Sâzende Nasib Hanım hakkında müstakil bir çalışmanın oluşturulması hem literatüre hem de yapılacak olan yeni çalışmalara katkı sağlaması bakımından önemli görülmektedir.

\section{Sinırlılıklar}

Bu çalışma; Hânende-Sâzende Nasib Hanım ve kardeşi Mehmet Bey ile sınırlandırılmıştır. 


\section{Yöntem}

$\mathrm{Bu}$ derleme tipi çalışmada nitel araştırma yöntemi kullanılmış olup konu kaynakları, tarama modeliyle bir araya getirilmeye çalışılmıştır. Nasib Hanım ile ilgili klasik ve akademik kaynaklar taranarak elde edilen veriler incelenmiş ve bir bütün içerisinde toparlanarak konu bağlamında genel bir değerlendirme yapılmıştır.

\section{Veri Toplama Araçları}

Nasib Hanım hakkında gerekli bilgilerin elde edilebilmesi için literatürde bu hususta yazılmış makale, kitap, internet siteleri, gazete yazıları, gazete küpürleri ve plaklar taranmıştır.

\section{Türkiye’de Plakların Gelişim Süreci}

Ülkemizde ses kaydının başlangıcı gramofon plaklarıyla olmuştur. İlk dönemlerde Müslüman halkın müziği geçim unsuru olarak kullanamamasının nedeni: Toplumda itibar zedeleyen, ayıp görülebilecek bir anlayışın mevcut olduğundandır. Bu dönemde kadınların ses kayıtlarında yer almaları da pek uygun görülmemekteydi. Onlara engel teşkil edecek birtakım gerekçeler bulunuyordu. $\mathrm{Bu}$ engellerden ilki dini gerekçelerdi. Bundan dolayı Osmanlı'da Çingene vatandaşlar ile Ermeni, Yahudi ve Rum vatandaşlar yani gayrimüslimler ilk okuyucular olmuşlardır. 1900 yılında başlayan bu sürece kadınların dahil olması ancak 1926-27 yıllarını bulmuştur (Ünlü, b.t.). Kadınların ses kaydı almalarındaki engellerden ikincisi ise kadın sesinin yükselmesinin uygun görülmemesiydi. Fakat Nasib Hanım’ın hemen hemen her akşam farklı konağın haremlik ve selamlığında yapılan fasıllarda (Özalp, b.t.) hem çalarak hem de söyleyerek sesini coşkuyla duyurduğu, halkın da bu sesi beğendiği bilinmektedir (Barutcu: 2019, 98).

Tanburi Cemil Bey'in oğlu Mesud Cemil'in Kalem Dergisinde yayımlanan makalesinde Nasib Hanım hakkında vermiş olduğu bilgiler çalışmamıza büyük katkı sağlamıştır. Mesud Cemil, tanıdığı musikişinaslardan bahsederken ilk olarak Nasib Hanım hakkında açıklamalarda bulunmaktadır; Nasib Hanım'ın herhangi bir saray eğitimi almayıp kendi yeteneğiyle halkın içinde yetiştiğini, yine aynı şekilde halkın sayesinde meşhur olduğunu ve bu cesareti, kabiliyetiyle adını her yerde duyurduğunu belirtir. Dönemin haremlik-selamlık anlayışı gereği erkeklere nazaran kadınların da musikiye olan ilgilerinde Nasip Hanım bu ihtiyaca bir deva olmuştur. Nasib Hanım'ın bu kadar rahat bir şekilde çekinmeden dönemin kadın-erkek örflerini kolayca aşması, onun halk içinde yetişmesi ve her tür insan tanımasından kaynaklı olduğunu da belirtmek gerekir. 
Terbiyesi, zekiliği, herkesten bir şeyler öğrenmeye olan azmi de dikkat çeken diğer bir unsurdur. Ayrıca Mesud Cemil, Nasib Hanım'ın kendilerinin evine de geldiğini, hatta annesi ile diğer kadınların o gün heyecanla yiyecekler, içecekler ve hediyeler hazırladığını anlatmaktadır (Cemil: 1962, 14-15). Eski İstanbul'u en güzel şekilde ayrıntılarıyla anlatan gazeteci-yazar Sermet Muhtar Alus'un Nasib Hanım hakkında yazdıkları da dikkate değerdir. Alus, 2 Nisan 1939 tarihli Akşam gazetesindeki yazısında Nasib Hanım'ın her hafta çok yoğun bir programının olduğunu, bu yüzden sürekli kâhya, ağa efendi ile haber göndermek gerektiğini, eğer uygun bir zaman dilimi yakalanırsa en az bir hafta önceden kendisiyle randevulaşmak gerektiğini belirtir. Nasib Hanım'ın kendisinden randevu almak isteyenlere ise şöyle cevaplar verdiği görülmektedir: "Yarın akşam Nişantaşında filan paşalardayım... Öbür gece Serencebey yokuşunda falan beyefendilere davetliyim... Çarşambayı hiç hesaba katmayın” (Alus, 1939: 8).

\section{Nasib Hanım'ın Hânendeliği}

Çingene asıllı müzisyenler arasında sâzendelik, hânendeliğe nazaran daha çok tercih edilmiştir. Hânendelik daha zayıf durumdadır denebilir (Altınöz: 2005, 261). Fakat Nasip Hanım, bu iki özelliği de kendinde barındıran mühim bir sanatçıydı. Ayrıca kendisinin iyi bir Çingene tarzı mani okuyucularından olduğu da belirtilmelidir (Hamarat: 2010, 246). Kaynaklarda geçen bilgilere bakılarak ses renginin alto sese yani tok ve gür bir sese sahip olduğu görülmektedir (Açıkgöz: 2018, 6). Bu bilgiden hareketle Nasib Hanım'ın bulunması güç olan plakları arasından “Hicaz Gazel” adlı plak kaydı dinlenebilmiş ve belirtildiği üzere davudi diyebileceğimiz ses rengine sahip olduğu anlaşılmıştır.

Günümüz üslûbundan farklı olarak 20. yüzyıl Türk müziği hânendelerinin icralarında sıkça görülen seri gırtlak hareketleri ve buna bağlı yapılan çarpmalar, bu dönemi diğerlerinden ayıran en önemli özelliklerden biri olmuştur. Dönemi ile bütünleşmiş taksim stilleri gibi hânendelerin çarpmaları da tıpkı bir enstrüman gibidir. Nasib Hanım'ın 78 devirli plaklara okumuş olduğu eserlerde çarpmalarının çok keskin olmadığı görülmektedir. Kendisinin daha çok yetiştiği ortam ve şartların getirdiği "Roman Tavrı" diyebileceğimiz bir tavra sahip olduğu söylenebilir. Bugün kulaklarda yer etmiş olan ve "Elmalıya vurgunum aman" olarak bilinen, Hicaz makamında, Kanto formundaki “Elmalı Kantosu” beste ve güftesiyle Nasib Hanım’a aittir. Onun tavrı özellikle bu bestesinden de anlaş1labilmektedir. 
Nasib Hanım'ın ülkemizde taş plak kaydında öncü kadınlardan olması, yukarıda belirtilen nedenlerden hareketle çingene asıllı olmasından kaynaklandığı gibi huluskâr bir özelliğe sahip olmasından da kaynaklıdır. Bunda etkili olan nedenlerin başında: İlk günden bugüne Çingeneler'in köylere nazaran hep şehirlerde yaşamaya yatkın olmaları ve yaşadıkları bölgelere uyum sağlamaları önemli bir etkendir. "Zira Çingeneler, kentlilerin ihtiyaç duyduğu hizmetleri yerine getiren ve onlarla açık ve/veya örtülü uyum sağlayabilen bir topluluktur. Bu bakımdan orta ve üst sosyal sinıflarla Çingeneler arasında muazzam bir iş/alışveriş ilişsisi vardır. "(Duygulu, 2018: 321) “Türkiye'de ilk plâğı dolduran Hafiz Aşır olmuştur. Daha sonra onu izleyenler Hafiz Osman, Hafiz Yaşar, Hanende İbrahim, Hanende Şahab, Hanende Nasip Hanım, Hafiz Burhan, Tamburi Cemil, Neyzen Tevfik, Kemençe Aleko, Udî Yorgo, Klârnet İbrahim, Hafiz Kemal Sadettin'dir. Ve bu saydı̆ğmı sanatçılar bizde plâk dolduranların öncüleridir." (Borcakl1, 1964: 43). Plak kayıtlarında kayıt türlerine bakılacak olunursa bunların gazeller, Kur'an tilavetleri, Mevlevi ayinleri, şarkılar üzerine olduğu görülmektedir. Her ne kadar başlarda kadınların ses kaydına uzak durmaları gibi bu durum olsa da 20. yüzyıldan itibaren mevcut endişelerin kırılmasıyla pek çok kadın hânende ses kaydına ilgi duymuş, kayıtlar yapmıştır (Çolakoğlu Sarı, 2013: 211).

Nasib Hanım'ın plaklarına günümüzde ulaşabilmek güçtür. Kendisine ait plakların piyasada çok az sayıda bulunmasından dolayı birçok sahaf ile iletişime geçilmiş olsa dahi bu plakların artık bulunamadığg görülmüştür. Araştırmalarımız sonucu kendisinin ses rengi, üslup ve tavrı hakkında kaynaklardan edinilmiş olan bilgiyi tasdikleyecek nitelikte üç plağı bulunabilmiş ve daha sağlkklı bilgiler yazılmasında katkı sağlamıştır. Bu hususta plaklar üzerine incelemeler yaparak genişçe bir arşiv oluşturan Op. Dr. Aybars Akkor ile bir görüşme gerçekleştirilmiş ve kendisinde Nasib Hanım'a ait üç taş plağın bulunduğu öğrenilmiştir. Dönemin kayıt teknolojisinde plağın sadece tek bir tarafına kayıt yapılabildiğinden dolayı üç ayrı plak olarak bulunan bu üç plak şunlardır: DağıKürdi Taksim, Ninni, Hicaz Gazel. Ayrıca kendisi Nasib Hanım hakkında şöyle bir değerlendirmede bulunmuştur: "Nasib Hanım ilk Türk taş plak sanatçısı olarak sayılsa da plak alanında yetkin olan Gökhan Akçura ile Cemal Ünlü, Nasib Hanım'ın ilk Osmanlı kadın taş plak sanatçısı sayılabileceğini, ilk Türk Kadın sanatçının ise Fikriye Hanım olduğunu belirtirler. Ses kaydının ilk yıllarında kadınların bu kayıtlara katılamamalarına ait gerekçelere rağmen Nasib Hanım hemen hemen her gece bir konakta hem hânendelik hem de sâzendelik yapmıştır." (A. Akkor, kişisel iletişim, 10 Ocak 2021). 
Nasib Hanım, 80 yaşında iken 6 Eylül 1934 Perşembe akşamı Harbiye'de Belvü Bahçesinde bir konser vermiştir. 5 Eylül 1934 yılı basılmış olan 18 gazete incelenmiş ve bunlardan yalnızca üçünde (Akşam Gazetesi, Cumhuriyet Gazetesi ve Son Posta Gazetesi) Nasib Hanım'a yer verildiği görülmüştür. Nasib Hanım'ın gazetelerdeki konser haberleri kendisi hakkında ulaşılabilen tek gazete küpürleri olarak gözükmektedir. Burada bahsedilmesi gereken bir diğer husus ise Belvü Bahçesi’nin önemidir.

Geçmişte İstanbul'da bahçeli lokanta, bahçeli kahve, bahçeli gazino gibi birçok mekan bulunmaktaydı. Önemli semtlerde birçok çalgılı mekanlar bulunuyordu. Belvü ise Harbiye'de bulunan önemli mekanlardan biriydi (Yesari: 1943, 4). Belvü Bahçeleri’nde Topal Sıdıka Hanım, Gazelhan Bohçacı Hatice Hanım (Alus: 1942, 5), Deniz Kızı Eftalya olarak bilinen Atanasia Yeorgiadu, Türk Sanat Müziği'nin nadide isimlerinden Müzeyyen Senar ve ülkemizde plağa okuyan ilk hanım hânende Nasib Hanım burada sahneye çıkmışlardır. Fakat bu dönemde pek çok sanatçının birkaç plak kaydı almalarıyla piyasadan çekildikleri görülür. Sanatçıları bu duruma sevk eden nedenler arasında sesin güzelliği yanında dinleyiciye karşı verilen imaj, görünüm de burada etkili olmuştur. Nasib Hanım' da bu durumdan etkilenenlerdendir. “Çingene asıllı Nasib Hanım'ın verdiği tek konserde kendisinin yaşlı ve çirkin olmasından dolayı seyirci kitlesinden yükselen kahkahalar ve ıslıklar, Nasib Hanım'ın umduğu zaferi tutmasına mâni olmuştur” (Barutcu, 2019: 98). Bahsedilen konser yukarıda da belirtildiği üzere kendisinin 80 yaşında iken Belvü Bahçesinde vermiş olduğu konserdir.

\section{Nasib Hanım'ın Sâzendeliği}

Yapılan araştırmalar ile Nasib Hanım'ın ud çaldığına dair tek fotoğrafı bulunmaktadır. Kendisinin bulunması pek kolay olmayan plaklarında uda nazaran daha çok hânendeliği üzerine kayıtlarda bulunduğu görülmüştür. Osmanlı'da bir piyasa udisi olan Nasib Hanım ile ilgili kaynaklarda yer alan tek fotoğraf ise aşağıda yer almaktadır. Mesud Cemil, 1900'lü yıllarda udu en çok kadınlar ve genç kızların icra ettiğini belirtir (Cemil, 1962: 9). Fakat yukarıda belirtildiği gibi Nasib Hanım sâzendelik ve hânendeliğini beraber yürütmüş olsa da hânendeliğiyle ön plana çıkmıştır.

Nasib Hanım’ın ilk kaydının 1900 yılının mayıs ayında bir ud taksimi ile başladığı belirtildiği gibi (Delen: 2020, 174) bu taksimin yer aldığı plağın 1903 tarihli olduğu da belirtilmelidir. "The Gramophone and Typewriter Ltd. and Sister Companies" etiketi ile 12479/544- AZ şeklinde numaraya sahip olan (Özdemir: 2009, 82) bu taksimin halk müziğgi havasında olduğu ve "Dağı- 
Kürdi Taksim” adıyla plak camiasında yer edindiği bilinmektedir (Ünlü: 2016, 141). Bu plak aynı zamanda koleksiyonerlerin ulaşabildiği en eski 78'lik taş plak kaydı özelliğini taşımaktadır (Akçura: 2001, 25).

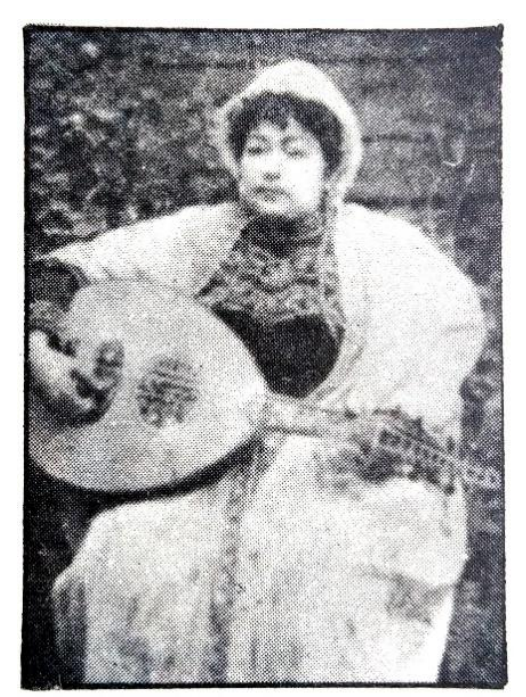

Fotoğraf 2. Nasib Hanım ud icra ederken.

Sâzendeliği hakkında pek bilgi bulunmadığından dolayı fotoğrafı üzerine bir değerlendirme yapma gereksinimi hissedilmiştir. Enstrümanı hakkında fikir veren unsurlara bakılacak olunursa, genellikle Türk udlarında pek görülmeyen tek kafese sahip bir udu olduğu görülmektedir. Tek kafesli udları genellikle Ermeni ud yapımcılarının tercih ettiği de belirtilmelidir. Ud, tekne şekli ve kafes tarzı ile yaygın kullanım bölgesi ve ustalarıyla özdeşleşir, ayırt edilebilir. Nasib Hanım'ın udunun tekne formu oval olup şekilleriyle özgünlüğünü elde etmiş olan Arap ve Türk udlarından ayrılmaktadır. Çünkü Ermeni udlarının yapısının en belirgin görünüş özelliği: tek ve büyük bir kafes ile oval bir tekneye sahip olmasıdır (Sarı, 1985). "Geçmişten günümüze ud yapımcılarını incelendiğinde karşılaşılan isimler arasında ilk dikkat çeken konu; Özellikle 19. ve 20. yy arasındaki yapımcıların genellikle ermeni asıllı Osmanlı vatandaşları olmasıdır. Aslına bakılırsa bu tarihlerde hemen hemen bütün el sanatlarının ermeni azınlıklar tarafindan gerçekleştirildiği görülmektedir." (Oter, 2007: 41). Diğer ayrıntılara bakılacak olunursa: Klavyesinin sade yahut işlemeli olduğu net bir şekilde anlaşılmasa da işlemeli gibi durmaktadır. Mızraplığı oval formda olup desenlerinden anlaşılacağı üzere yüksek ihtimalle bağadandır. 


\section{SONUÇ}

Nasib Hanım, 20. Yüzyılda ülkemize gelmiş olan taş plak kaydı serüveninde mühim bir yere sahip olduğu gibi dönemin piyasa müziğinde de adından sıkça bahsettiren önemli bir hanım hânende ve sâzendedir. Bu önemine binaen Nasib Hanım hakkında müstakil bir çalışmanın olmaması dikkatimizi çekmiş, incelenen tüm kaynaklarda kendisi hakkında bulunan en ufak bilgi dahi bizim için büyük önem arz etmiştir. Netice itibariyle elde edilebilen tüm bulgular çalışmada sunulmuş ve değerlendirilmeye çalışılmıştır. Bu çalışmada günümüzde yeterince tanınmayan, hakkında bir derleme çalışması yapılmamış olan Nasib Hanım’ın tanıtılmasına katkı sağlanması hedeflenmiştir. Ülkemizde 1900 yılında başlayan ses kayıt sürecinin ilk yıllarında kadınların dinsel-örfi gerekçelerden dolayı kayıtlara katılamamalarına rağmen Nasib Hanım, döneminin baskın olan haremlik-selamlık anlayışına karşın hiçbir çekince duymadan halkın içinde kendisini yetiştirerek ismini hanelere duyurabilmiş, bayanların da musiki ihtiyacına katkı sağlamış ve böylece bir hayran kitlesi oluşturabilmiştir. Onun bu meşhur olma serüveninde terbiyesi, zekiliği, ses tonunun farklılığg, herkesten bir şeyler öğrenmeye olan azmi de dikkat çeken diğer unsurlardır. Şüphesiz sahne hayatında tavır, üslup ve ses güzelliğinin yanı sıra dinleyiciye karşı verilen imaj da etkili nedenler arasındadır. Ulaşılabilen bilgilere göre bir defa konser verebilmiş olan Nasib Hanım yaşı ve fiziksel özelliklerinden dolayı gördüğü tepkiler karşısında umduğunu bulamasa da ünü zamanın birçok hanesinde duyulmuştur. Bundan dolayı kendisinin tanıtılması, bir değer olarak literatüre kazandırılması gerektiği düşünülmektedir. Ayrıca bu çalışma, ileride yapılacak olan yeni araştırmalara katkı sağlaması bakımından önemli görülmektedir. Nasib Hanım gibi daha pek çok değerli musikişinas araştırılmayı, literatürde yer etmeyi beklemektedir.

\section{KAYNAKLAR}

Açıkgöz, M. A. (2018). Rehber-i Âşık ve Salât-ı Nevâfil Adlı Mecmua, Amasya Üniversitesi Türk Dili ve Edebiyatı Öğrenci Bilim Şöleni, Bildiri, Amasya. 3-13.

Akçura, G. (2001). Ivır Zıvır Tarihi I “Unutma Beni”, Om Yayınevi, İstanbul.

Altınöz, İ. (2005). Osmanlı Toplumunda Çingeneler, İstanbul Üniversitesi, Sosyal Bilimler Enstitüsü, Tarih Anabilim Dal1, Doktora Tezi, İstanbul.

Alus, S. M. Kırk Yıl Evvelkiler: Piyasadaki Hanendeler, Akşam, 2 Nisan 1939, s. 8. https://www.gastearsivi.com/gazete/aksam/1939-04-02/8 (Erişim tarihi: 10 Şubat 2021). 
Alus, S. M. Gördüklerim, duyduklarım: Kuşdili kontu, Akşam, 18 Kasım 1942, s. 5. https://www.gastearsivi.com/gazete/aksam/1942-11-18/5 (Erişim tarihi: 9 Mart 2021).

Borcakl1, A. (1964). Gramofon Plaklart (Modern Kütüphanecinin Çetin Sorunu), Türk Kütüphaneciler Derneği Bülteni Cilt: 13, Sayı: 1-2, 43-46.

Barutcu, T. (2019). Taş Plak Geleneğinde Türk Müziği Kadın Ses Sanatçılarının Müzikal Kimlik ve Rolleri . Afyon Kocatepe Üniversitesi Akademik Müzik Araştırmaları Dergisi, 5 (10), 83-107.

Cemil, M. (1962). Tanıdiğım Musikişinaslar, İstanbul, Kalem - Haftalık Faydalı Bilgiler Dergisi, Cilt: 1, Sayı: 2.

Çolakoğlu Sarı, G. (2013). Osmanlı'dan Cumhuriyet'e Kadın Müzisyenler: Taş Plak Geleneğinde Lale ve Nerkis Hanımlar CD'si, İTÜ Türk Musikisi Devlet Konservatuarı Uluslararası Porte Akademik Müzik ve Dans Araştırmaları Dergisi Gender Özel Sayısı, İstanbul, No. 6, 208-216.

Delen, H. (2020). "Ülkemizdeki İlk Kayltlardan Günümüze Geleneksel Türk Müziği Topluluklarında Kullanılan Kayıt Yöntemleri”, International Social Mentality and Researcher Thinkers Journal, (Issn:2630-631X) 6(28): 171-181.

Duygulu, M. (2018). Çingeneler Müzisyenlik ve Değişen Sosyal Koşulların Müzisyen Kimliğine Etkisi, MSGSÜ Sosyal Bilimler Dergisi, 2 (18): 320-326.

Güntekin, M. (2010). İstanbul'un 100 Musikişinası, İstanbul: İstanbul Büyükşehir Belediyesi Kültür A.Ş. Yayınları.

Hamarat, Z. (2010). Ahmed Rasim 'in Eserlerinde Ístanbul Folkloru, İstanbul Üniversitesi, Sosyal Bilimler Enstitüsü, Türk Dili ve Edebiyatı Anabilim Dalı, Türk Halk Edebiyatı Bilim Dalı, Yüksek Lisans Tezi, İstanbul.

İnal, İ. M. K. (1958). Hoş Sadâ-Son Asır Türk Musikişinasları, İstanbul: Maarif Basımevi.

Oter, T. (2007). Geçmişten Günümüze Ud Yapımcıları, Ud Yapımında Kullanılan Yöntemler, Selçuk Üniversitesi Sosyal Bilimler Enstitüsü Müzik Anabilim Dalı Türk Sanat Müziği Bilim Dalı, Yüksek Lisans Tezi, Konya.

Özdemir, S. (2009). Popülerleşme Sürecinde Türk Müziği ve Bu Süreçte Bir Bestekar: Sadettin Kaynak, İstanbul Teknik Üniversitesi, Sosyal Bilimler Enstitüsü, Doktora Tezi, İstanbul.

Özden, E. (2013). Mûsıkîşinas-ı Şehir Tanbûrî Cemil Bey'in Artistik Plaklarının Husûsî Kataloğu ve Cemil Bey’in Tuttuğu Notlar, Çukurova Üniversitesi İlahiyat Fakültesi Dergisi 13 (1), 211-227.

Öztuna, Y. (1987). Dede Efendi, Kültür Bakanlı̆̆ı Yayınları, İstanbul. 
Ünlü, C. (2016). Git Zaman, Gel Zaman Fonograf-Gramafon-Taş Plak, İstanbul: Pan Yayıncıllk.

Yesari, M. Eskiden yeniden: İstanbul'un bahçeleri, Haber (Akşam Postası), 28 Eylül 1943, s. 4. https://core.ac.uk/download/pdf/38305824.pdf (Erişim tarihi: 26 Ocak 2021).

Yılgür, E. (2006). İstanbul Çingeneleri: Karşıllksız Bir Aşk Hikayesi. İstanbul Dergisi, Sayı: 57.

İnternet: Ünlü, C. (b.t). Türk ses kaylt tarihi. Turkish Music Portal. http://www.turkishmusicportal.org/tr/turk-muzigi-tarihi/turk-ses-kayit-tarihi (Erişim tarihi: 06 Ocak 2021).

İnternet: Sarı. A. (1985). Ud Yapımcısı Temel Şehit Görüşmesi. Musiki Dergisi. http://www.arsiv2007.musikidergisi.net/?p=15 (Erişim tarihi: 9 Ocak 2021).

İnternet: Özalp, N. (b.t.). Suphi Ziya Özbekkan. Esendere Kültür Sanat Derneği. http://www.eksd.org.tr/suphi-ziya-ozbekkan/ (Erişim tarihi: 9 Şubat 2021). 